Article

\title{
Cool Temperature Enhances Growth, Ferulic Acid and Flavonoid Biosynthesis While Inhibiting Polysaccharide Biosynthesis in Angelica sinensis
}

\author{
Han Dong ${ }^{1}$, Meiling Li ${ }^{2}$, Ling Jin ${ }^{1}$, Xiaorong Xie ${ }^{1, *}$, Mengfei Li $^{2, *(D)}$ and Jianhe Wei ${ }^{3}$ \\ 1 College of Pharmacy, Gansu University of Chinese Medicine, Lanzhou 730030, China; \\ dongaa10245@163.com (H.D.); jinl@gszy.edu.cn (L.J.) \\ 2 State Key Laboratory of Aridland Crop Science, Gansu Agricultural University, Lanzhou 730070, China; \\ mlli1996@163.com \\ 3 Institute of Medicinal Plant Development, Chinese Academy of Medical Sciences and Peking Union Medical \\ College, Beijing 100193, China; jhwei@implad.ac.cn \\ * Correspondence: gszyxxr@163.com (X.X.); lmf@gsau.edu.cn (M.L.)
}

check for

updates

Citation: Dong, H.; Li, M.; Jin, L.; Xie,

X.; Li, M.; Wei, J. Cool Temperature Enhances Growth, Ferulic Acid and Flavonoid Biosynthesis While Inhibiting Polysaccharide Biosynthesis in Angelica sinensis. Molecules 2022, 27, 320. https:// doi.org/10.3390/molecules27010320 Academic Editors: Giuseppe Dionisio and Vittorio Calabrese

Received: 10 December 2021

Accepted: 4 January 2022

Published: 5 January 2022

Publisher's Note: MDPI stays neutral with regard to jurisdictional claims in published maps and institutional affiliations.

Copyright: (C) 2022 by the authors. Licensee MDPI, Basel, Switzerland. This article is an open access article distributed under the terms and conditions of the Creative Commons Attribution (CC BY) license (https:// creativecommons.org/licenses/by/ $4.0 /)$.

\begin{abstract}
Angelica sinensis, a perennial herb that produces ferulic acid and phthalides for the treatment of cardio-cerebrovascular diseases, prefers growing at an altitude of 1800-3000 m. Geographical models have predicted that high altitude, cool temperature and sunshade play determining roles in geo-authentic formation. Although the roles of altitude and light in yield and quality have been investigated, the role of temperature in regulating growth, metabolites biosynthesis and gene expression is still unclear. In this study, growth characteristics, metabolites contents and related genes expression were investigated by exposing $A$. sinensis to cooler $\left(15^{\circ} \mathrm{C}\right)$ and normal temperatures $\left(22^{\circ} \mathrm{C}\right)$. The results showed that plant biomass, the contents of ferulic acid and flavonoids and the expression levels of genes related to the biosynthesis of ferulic acid (PAL1, 4CLL4, 4CLL9, C3H, $H C T, C C O A M T$ and $C C R$ ) and flavonoids ( $C H S$ and $C H I$ ) were enhanced at $15^{\circ} \mathrm{C}$ compared to $22{ }^{\circ} \mathrm{C}$. The contents of ligustilide and volatile oils exhibited slight increases, while polysaccharide contents decreased in response to cooler temperature. Based on gene expression levels, ferulic acid biosynthesis probably depends on the CCOAMT pathway and not the COMT pathway. It can be concluded that cool temperature enhances plant growth, ferulic acid and flavonoid accumulation but inhibits polysaccharide biosynthesis in A. sinensis. These findings authenticate that cool temperature plays a determining role in the formation of geo-authentic and also provide a strong foundation for regulating metabolites production of $A$. sinensis.
\end{abstract}

Keywords: Angelica sinensis; cool temperature; growth; ferulic acid biosynthesis; flavonoid biosynthesis; gene expression

\section{Introduction}

Angelica sinensis (Oliv.) Diels, commonly named as Dang gui, Dong quai and Tang kuei, is a perennial herb that grows at an altitude of 1800-3000 $\mathrm{m}$ with cool, moist and partial shade conditions [1,2]. The roots of $A$. sinensis, one of the most important herbal drugs in traditional Chinese medicine, are used for nourishing blood, regulating female menstrual disorders and relieving pains and relaxing bowels [1,3,4]. More recently, interest has focused on its potential cardio-cerebrovascular, hepatoprotective, antioxidant, antispasmodic and immunomodulatory effects [1]. Currently, over 140 constituents that have been identified from the roots mainly include the following: organic acids (e.g., ferulic acid, coniferyl ferulate and succinic acid), phthalides (e.g., ligustilide, butylidenephthalide and butylphthalide), polysaccharides (e.g., fucose, galactose and glucose) and flavonoids [4]. The main actives compounds in the roots are considered to be the following: organic acids, phthalides and polysaccharides [5]. 
A. sinensis is originally native to China with a population center in Gansu province as well as cultivated in western regions, including the following: Qinghai, Sichuan and Yunnan provinces $[1,2,6]$. Minxian county and surrounding counties (e.g., Tanchang, Zhangxian, Weiyuan, Zhuoni and Lintan) of Gansu province are known as the geo-authentic areas due to roots containing more bioactive compounds [2,7,8]. Analyses on geo-authentic A. sinensis grown in Gansu region have deduced that altitude, temperature, sunshine and rainfall are the most influential ecological factors for the accumulation of bioactive compounds (ferulic acid, ligustilide, chlorogenic acid, coniferyl ferulate, senkyunolide A, senkyunolide $\mathrm{H}$, senkyunolide I, butenyl phthalide and levistilide A) $[9,10]$. Investigations into the role of altitude (ca. 2000-2900 m) have found that there is a positive correlation of altitude with the contents of ferulic acid, volatile oils (i.e., ligustilide and butenyl phthalide), polysaccharides, flavonoids and phenolics, while moderate altitude (ca. 2500-2600 m) is favorable for root biomass [11-18].

Generally, altitude affects climate by decreasing temperatures and increasing light intensity and rainfall. Previous studies have demonstrated that reducing light intensity with $50-75 \%$ of sunshade can increase root yield and ferulic acid accumulation, meanwhile indirectly decreasing temperature and increasing moisture of air and soil [19,20]; on the other hand, UV-B radiation can increase phthalide accumulation [21]. Although $A$. sinensis plants prefer moist conditions, the excessive soil water can induce fleshy roots to rot, and soil drought will result in a significant decrease in root yield as well as ferulic acid and volatile oils contents [1,22].

For the biosynthesis pathways of ferulic acid, flavonoids and phthalides, previous literature has reported that the biosynthesis of ferulic acid and flavonoids belongs to the phenylpropanoid pathway (Figure 1). Specifically, ferulic acid biosynthesis is synthesized via two sub-pathways, including the following: (1) caffeic acid 3-O-methyltransferase (COMT) pathway involved in enzymes such as cinnamate 4-hydroxylase $(\mathrm{C} 4 \mathrm{H}), p$-coumarate 3 hydroxylase $(\mathrm{C} 3 \mathrm{H})$ and COMT; and (2) caffeoyl-CoA 3-O-methyltransferase (CCOAMT) pathway involved in enzymes such as 4-coumarate-CoA ligase (4CL), hydroxycinnamoyl shikimate transferase (HCT) and CCOAMT. Flavonoid biosynthesis was catalyzed by enzymes such as chalcone synthase (CHS) and chalcone isomerase (CHI) $[23,24]$. On the other hand, the biosynthesis pathway of phthalides, especially in ligustilide, and the genes that participate in regulating the biosynthesis are still limited $[9,25,26]$.

To date, plant growth, bioactive metabolites accumulation and related genes expression in $A$. sinensis in response to temperatures have not been examined. In this study, we probe the role of temperatures in growth, metabolites biosynthesis and genes expression related to ferulic acid, flavonoids, volatile oils and polysaccharides to identify links between cooler growing temperatures and the formation mechanism of geo-authentic medical materials of $A$. sinensis. 


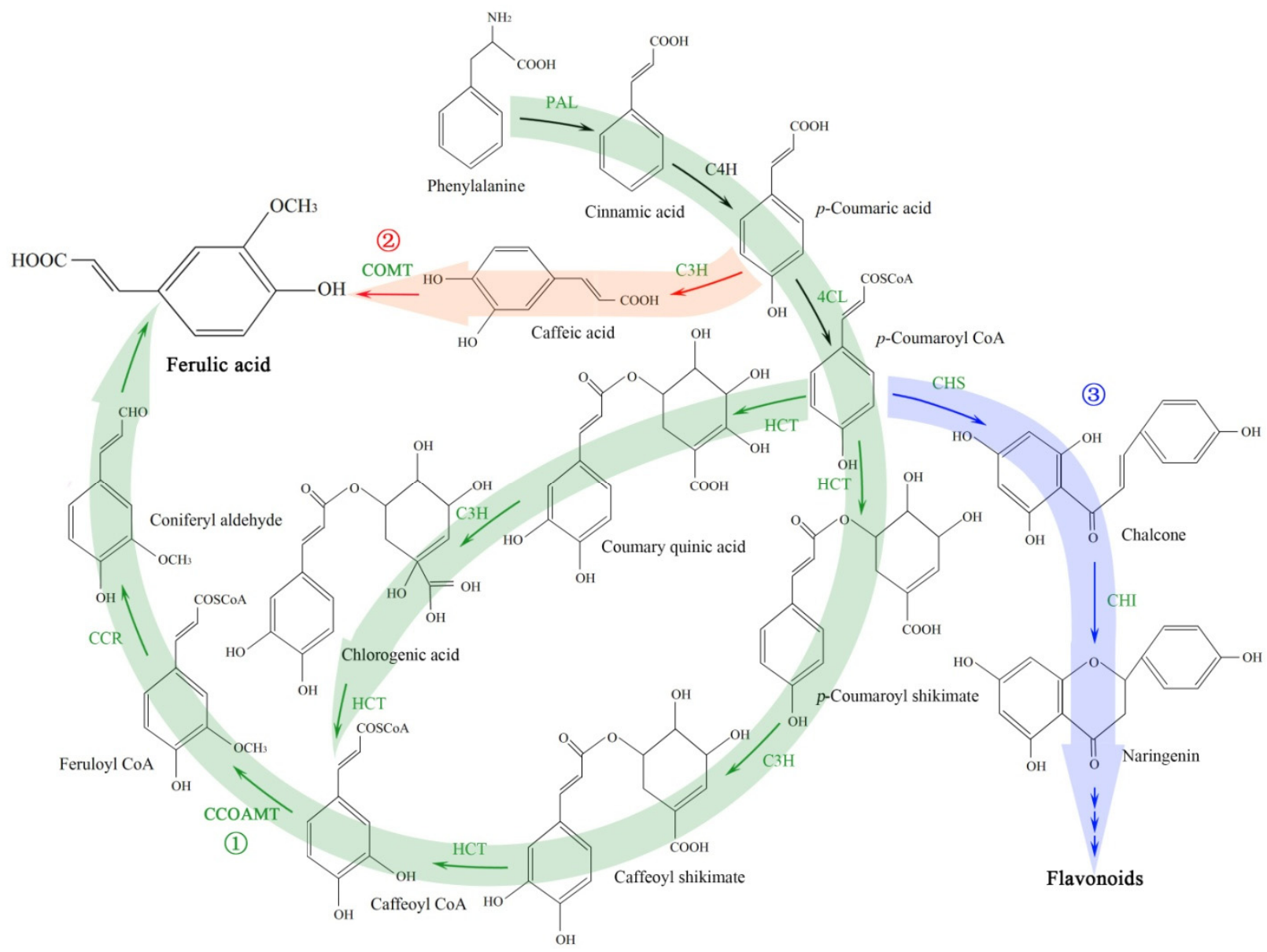

Figure 1. Schematic representation of biosynthetic pathways leading from shikimic acid pathway to phenylpropanoid pathway. Solid arrow indicates known steps, whereas multiple arrows indicate multiple reaction steps. Enzyme abbreviations are as follows: EMB3004, Bifunctional 3-dehydroquinate dehydratase/shikimate dehydrogenase, chloroplastic; CM, chorismate mutase; $\mathrm{PAL}$, phenylalanine ammonia lyase; $\mathrm{C} 4 \mathrm{H}$, cinnamate 4-hydroxylase; 4CL, 4-coumarate-CoA ligase; HCT, hydroxycinnamoyl shikimate transferase; $\mathrm{C} 3 \mathrm{H}, p$-coumarate 3-hydroxylase; CCOAMT, caffeoyl-CoA 3-O-methyltransferase; CCR, cinnamoyl CoA oxidoreductases; COMT, caffeic acid 3-O-methyltransferase; $\mathrm{CHS}$, chalcone synthase; $\mathrm{CHI}$, chalcone isomerase. (1) Showing the ferulic acid biosynthesis via CCOAMT sub-pathway; (2) Showing the ferulic acid biosynthesis via COMT sub-pathway; (3) Showing the flavonoid biosynthetic sub-pathway.

\section{Results}

\subsection{Effect of Temperatures on Growth Characteristics}

Fresh and dry weights (FW and DW) of whole plants were 1.19-fold and 1.51-fold greater at $15{ }^{\circ} \mathrm{C}$ than $22{ }^{\circ} \mathrm{C}$, which largely relied on a 1.41 -fold and 1.47-fold increase in FW and DW of roots (Figure 2A,B). Additionally, there was a 1.58-fold and 1.10-fold increase in stem and root diameters (Figure 2C,D), while no significant difference in shoot height and root length was observed between $15^{\circ} \mathrm{C}$ and $22{ }^{\circ} \mathrm{C}$ (Figure $2 \mathrm{E}, \mathrm{F}$ ).

2.2. Effect of Temperatures on Contents of Ferulic Acid, Flavonoids, Ligustilide, Volatile Oils and Polysaccharides

Ferulic acid and flavonoids contents in roots were 1.90-fold and 1.42-fold greater at $15{ }^{\circ} \mathrm{C}$ than $22{ }^{\circ} \mathrm{C}$ (Figure $3 \mathrm{~A}, \mathrm{~B}$ ). Ligustilide and volatile oils contents exhibited a 1.01-fold and 1.15 -fold increase at $15^{\circ} \mathrm{C}$, while there was no significant difference compared to $22^{\circ} \mathrm{C}$ (Figure 3C,D). Polysaccharides content significantly decreased with a reduction of 0.86 -fold at $15{ }^{\circ} \mathrm{C}$ compared to $22{ }^{\circ} \mathrm{C}$ (Figure 3E). 

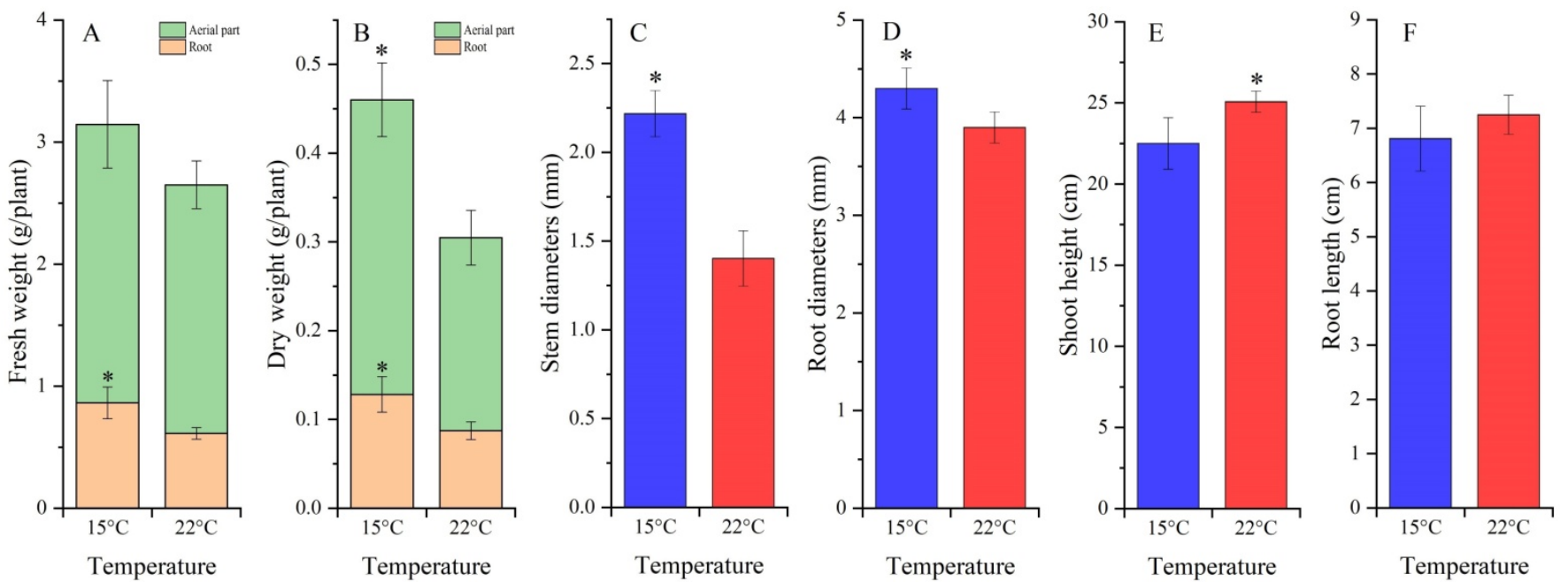

Figure 2. Growth characteristics in $A$. sinensis treated with cool temperature (mean $\pm S D, n=20$ ). Images $(\mathbf{A}, \mathbf{B})$ represent the FW and DW of the entire plant, $(\mathbf{C}, \mathbf{D})$ represent the stem and root diameters and $(\mathbf{E}, \mathbf{F})$ represent the shoot height and root length. " $* "$ represents a significant difference $(p<0.05)$ at different stages. The same below.
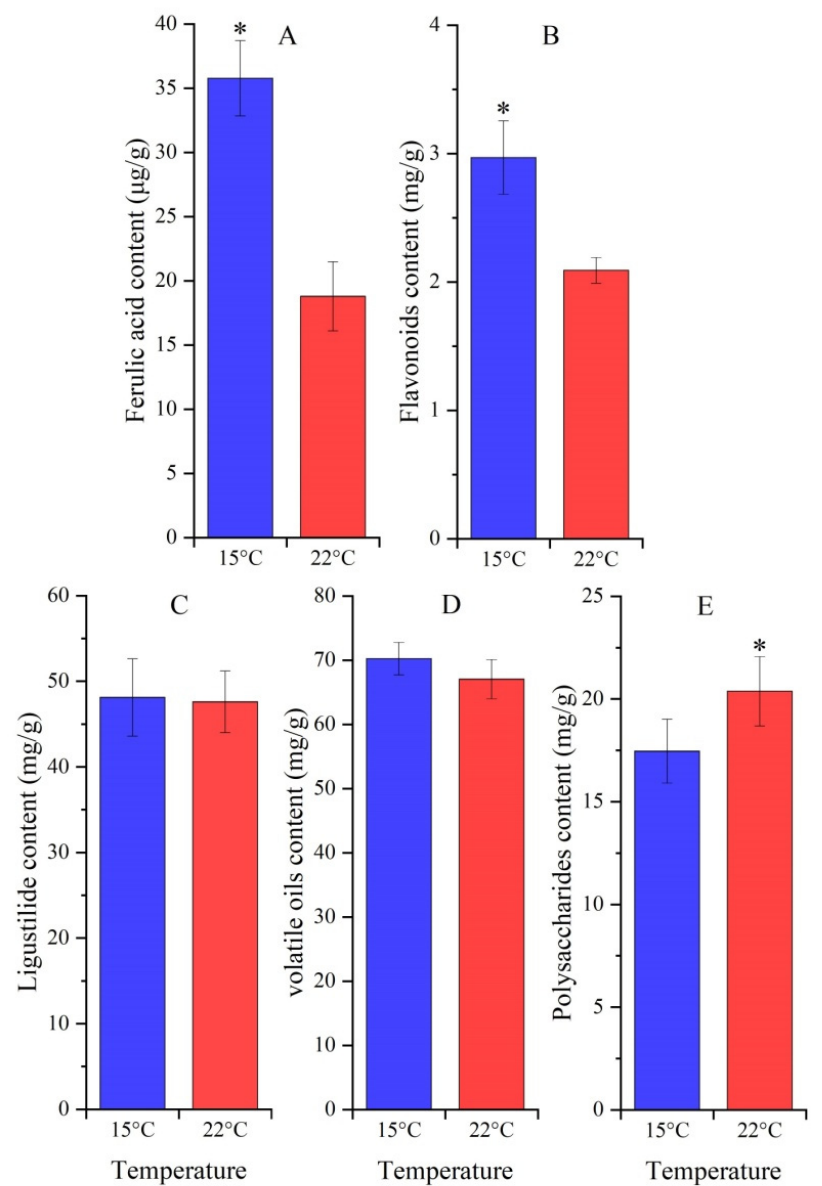

Figure 3. Metabolites contents in $A$. sinensis treated with cool temperature (mean $\pm S D, n=20$ ). Images $(\mathbf{A}, \mathbf{B})$ represent the ferulic acid and flavonoids contents, $(\mathbf{C}, \mathbf{D})$ represent the ligustilide and volatile oils contents and (E) represents the polysaccharides content, respectively. "**" represents a significant difference $(p<0.05)$ at different stages. 
2.3. Effect of Temperatures on Gene Expression Related to Ferulic Acid and Flavonoid Biosynthesis

The mRNA expression levels of 10 genes related to ferulic acid biosynthesis (PAL1, 4CLL4, 4CLL5, 4CLL7, 4CLL9, HCT, C3H, CCOAMT, CCR1 and COMT1) and four genes related to flavonoid biosynthesis (CHS, CHI, GT6 and $I 3^{\prime} H$ ) in roots at 15 and $22{ }^{\circ} \mathrm{C}$ were quantified. For ferulic acid biosynthesis, the relative expression levels (RELs) of seven genes, PAL1, 4CLL4, 4CLL9, HCT, C3H, CCOAMT and CCR1, exhibited an upregulation of 8.05-fold, 3.65-fold, 2.74-fold, 2.50-fold, 11.48-fold, 10.82-fold and 3.60-fold, while the other three genes, 4CLL5, 4CLL7 and COMT1, exhibited a downregulation of 0.65-fold, 0.35-fold and 0.18 -fold, respectively, at $15{ }^{\circ} \mathrm{C}$ compared to $22{ }^{\circ} \mathrm{C}$ (Figure 4 ). For flavonoid biosynthesis, the RELs of the two genes $\mathrm{CHS}$ and $\mathrm{CHI}$ exhibited an upregulation of 4.16-fold and 3.65-fold, while the other two genes GT6 (UDP-glucose flavonoid 3-O-glucosyltransferase 6) and $13^{\prime} \mathrm{H}$ (isoflavone $3^{\prime}$-hydroxylase) exhibited a downregulation of 0.95 -fold and 0.40 -fold, respectively, at $15{ }^{\circ} \mathrm{C}$ compared to $22{ }^{\circ} \mathrm{C}$ (Figure 5).

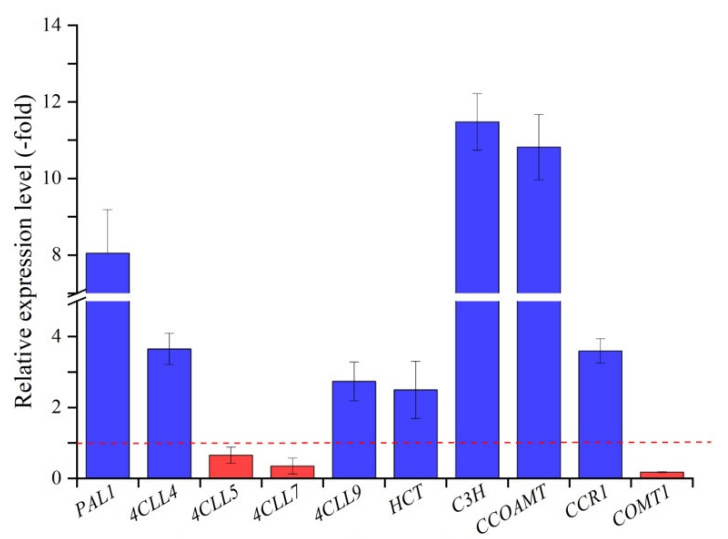

Genes involved in ferulic acid biosynthesis

Figure 4. Expression levels of ten genes related to ferulic acid biosynthesis in $A$. sinensis. Histograms show the relative expression level in response to $15{ }^{\circ} \mathrm{C}$ compared to $22{ }^{\circ} \mathrm{C}$. The same below. Abbreviations: PAL1, phenylalanine ammonia lyase 1; 4CLLs, 4-coumarate-CoA ligase like proteins; $\mathrm{HCT}$, hydroxycinnamoyl shikimate transferase; $\mathrm{C} 3 \mathrm{H}, p$-coumarate 3-hydroxylase; CCOAMT, caffeoyl-CoA 3-O-methyltransferase; CCR1, cinnamoyl CoA oxidoreductase 1; COMT1, caffeic acid 3-O-methyltransferase 1 .

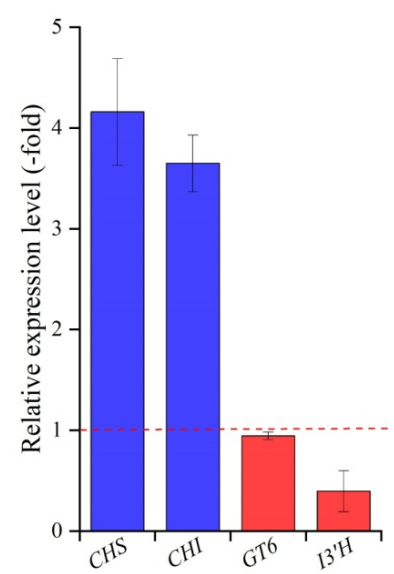

Genes involved in flavonoid biosynthesis

Figure 5. Expression levels of four genes related to flavonoid biosynthesis in A. sinensis. Abbreviations: CHS, chalcone synthase; $\mathrm{CHI}$, chalcone isomerase; GT6, UDP-glucose flavonoid 3-Oglucosyltransferase 6; $\mathrm{I}^{\prime} \mathrm{H}$, isoflavone $3^{\prime}$-hydroxylase. 


\subsection{Effect of Temperatures on Gene Expression Related to Volatile Oils and Polysaccharide Biosynthesis}

The mRNA expression levels of two genes related to volatile oils biosynthesis (transanol O-methyltransferase 1 (AIMT1) and acetyl-CoA-benzylalcohol acetyltransferase (BEAT)) and three genes related to polysaccharide biosynthesis (sucrose synthase isoform 1 (SUS1), pancreatic alpha-amylase (Amy2) and granule-bound starch synthase 1 (WAXY)) in roots at 15 and $22^{\circ} \mathrm{C}$ were quantified. For volatile oil biosynthesis, the RELs of the two genes, AIMT1 and $B E A T$, exhibited an upregulation of 1.11-fold and 1.10-fold, respectively (Figure 6). For polysaccharide biosynthesis, the RELs of the two genes SUS1 and WAXY exhibited an upregulation of 8.91-fold and 5.16-fold, while gene Amy2 exhibited a downregulation of 0.44 -fold, respectively, at $15^{\circ} \mathrm{C}$ compared to $22{ }^{\circ} \mathrm{C}$.

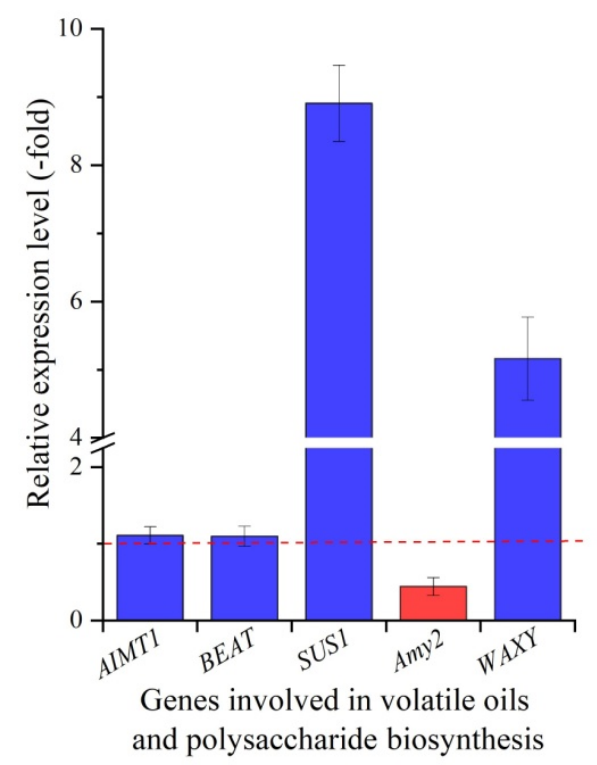

Figure 6. Expression levels of five genes related to volatile oils and polysaccharide biosynthesis in $A$. sinensis. Abbreviations: AIMT1, trans-anol O-methyltransferase 1; BEAT, acetyl-CoA-benzylalcohol acetyltransfe-rase; SUS1, sucrose synthase isoform 1; Amy2, pancreatic alpha-amylase; WAXY, granule-bound starch synthase 1 .

\section{Discussion}

The formation of geo-authentic herbs not only lays on the human society and species but also natural environmental conditions $[7,25]$. Previous studies have found that the geoauthentic formation of $A$. sinensis depends on geographic environmental conditions (e.g., higher altitude, cooler temperature and less sunshine) $[2,4,6,10]$. In this study, we found that cooler temperatures enhanced root biomass, ferulic acid and flavonoids accumulation and related genes expression; and inhibited polysaccharide biosynthesis, while it did not significantly affect ligustilide accumulation.

A significant increase in plant biomass was observed at cooler temperatures of $15{ }^{\circ} \mathrm{C}$ than $22^{\circ} \mathrm{C}$, which mainly resulted from the significant increase in root diameter (Figure 2). The increase in plant biomass at $15^{\circ} \mathrm{C}$ authenticates that the $A$. sinensis species prefers cool environmental conditions, which is accordance with previous studies that higher-altitude improves the root yield and bioactive metabolites accumulation [11,12,14]. Several studies have found that cooler temperatures are conducive to plant growth and root biomass, such as increases in root diameter and biomass of Sinopodophyllum hexandrum seedings at $15^{\circ} \mathrm{C}$ compared to $22^{\circ} \mathrm{C}[15,26]$; hairy roots biomass of Panax ginseng at $20^{\circ} \mathrm{C} / 13^{\circ} \mathrm{C}$ compared to $25^{\circ} \mathrm{C}$ and $35^{\circ} \mathrm{C} / 25^{\circ} \mathrm{C}$ [27]; and whole plant biomass of Hypericum perforatum at $15^{\circ} \mathrm{C}$ compared to $22^{\circ} \mathrm{C}$ [28].

The accumulation of plant secondary metabolites is often affected by environmental factors, such as light, water and temperature [29]. Low temperatures are one of the most 
important factors regulating phenylpropanoid metabolism [30]. Both ferulic acid and flavonoid biosynthesis pathways belong to the phenylpropanoid metabolism and employ the same genes, $P A L, C 4 H$ and $4 C L$ (Figure 1). In this study, a significant increase in ferulic acid and flavonoids contents was observed at $15^{\circ} \mathrm{C}$ compared to $22{ }^{\circ} \mathrm{C}$ (Figure 3A,B), which largely relied on upregulation of genes related to ferulic acid (i.e., PAL1, 4CLL4, $4 C L L 9, C 3 H, H C T, C C O A M T$ and $C C R$ ) and flavonoid biosynthesis (i.e., $C H S$ and $C H I$ ) (Figures 1,4 and 5). A significant downregulation of COMT1 (Figure 4) indicates that ferulic acid biosynthesis depends on not COMT but the CCOAMT pathway (Figure 1).

In addition, with respect to the two genes $4 C L L 5$ and $4 C L L 7$ that were downregulated at $15{ }^{\circ} \mathrm{C}$ compared to $22{ }^{\circ} \mathrm{C}$, the gene $4 C L L 5$ was found to contribute to jasmonic acid biosynthesis [31], and gene 4CL7 encodes enzyme 4CL7 that had no catalytic activity toward hydroxycinnamic acid compounds [32], which indicate that two genes 4CLL5 and $4 C L L 7$ do not participate in the ferulic acid biosynthesis. For the other two genes GT6 and $I 3^{\prime} \mathrm{H}$ that were downregulated at $15^{\circ} \mathrm{C}$ compared to $22{ }^{\circ} \mathrm{C}$, gene GT6 is involved in xenobiotic metabolism [33], and gene $I 3^{\prime} H$ is involved in the biosynthesis of pterocarpan phytoalexins [34]; both GT6 and $I 3^{\prime} H$ are required for pathogen defense and insect-induced responses $[35,36]$. The downregulation of two genes GT6 and $I 3^{\prime} H$ further confirms that the $A$. sinensis species is an alpine plant that prefers a cool environment.

No significant increase in ligustilide and volatile oils contents was observed at $15{ }^{\circ} \mathrm{C}$ compared to $22{ }^{\circ} \mathrm{C}$ (Figure $3 \mathrm{C}, \mathrm{D}$ ), which is consistent with the slight upregulation of two genes AIMT1 and BEAT involved in volatile oils biosynthesis (Figure 6). For the biological functions, gene AIMT1 is involved in the conversion of anethole and isoeugenol to isomethyleugenol, which are the primary constituents of volatile oils [37], and gene $B E A T$ is involved in the biosynthesis of benzyl acetate [38].

For the polysaccharide accumulation, a significant decrease was observed at $15{ }^{\circ} \mathrm{C}$ compared to $22^{\circ} \mathrm{C}$ (Figure 3E), while the three genes SUS1, Amy2 and WAXY were observed to be differentially regulated at $15{ }^{\circ} \mathrm{C}$, with upregulation for SUS1 and WAXY and, on the other hand, downregulation for Amy2 (Figure 6). For biological functions, gene SUS1 is involved in sucrose cleaving, which provides UDP-glucose and fructose for various metabolic pathways such as glycolysis [39]; gene WAXY is involved in starch and glycan biosynthesis [40]; and the gene Amy2 is involved in starch hydrolase [41]. In this study, the upregulation of the gene SUS1 may degrade polysaccharides to glucose and fructose, which provide energy to adapt to cooler temperatures. The upregulation of gene WAXY and downregulation of gene Amy 2 may promote starch accumulation, which results in greater plant biomass at $15^{\circ} \mathrm{C}$ than $22^{\circ} \mathrm{C}$.

\section{Materials and Methods}

\subsection{Plant Material}

Seedlings of Angelica sinensis (cultivar Mingui 1) with root-tip diameter $0.4-0.5 \mathrm{~cm}$ (see Figure S1) were selected to plant in pots $(13 \mathrm{~cm} \times 9 \mathrm{~cm})$ with soil (coconut coir: peat: fermented cow dung: pearlite $=3: 3: 2: 2$ ) and to germinate in a growth chamber with a constant temperature $\left(18^{\circ} \mathrm{C}\right)$ and a photoperiod cycle $\left(16 / 8 \mathrm{~h} \mathrm{light} /\right.$ dark, $\left.500 \mu \mathrm{mol} \cdot \mathrm{m}^{-2} \cdot \mathrm{s}^{-1}\right)$. After 15 days, plantlets that contained two leaves (see Figure S2) were moved to a growth chamber set at a constant temperature of 15 or $22^{\circ} \mathrm{C}$. After 30 days growth (see Figure S3), plants were harvested for physiological measurement, metabolites determination and mRNA quantification. Herein, higher temperatures such as $30^{\circ} \mathrm{C}$ is excluded from treatments because $A$. sinensis is an alpine plant that prefers a cool environment with average annual temperatures ranging from 4 to $9{ }^{\circ} \mathrm{C}[1,2,9]$.

\subsection{Physiological Measurement}

After temperature-treated plants were removed from pots and rinsed with tap water, shoot height $(\mathrm{cm})$, stem diameter $(\mathrm{mm})$, root length $(\mathrm{cm})$, diameter $(\mathrm{mm})$, fresh weight $(\mathrm{FW}$, $\mathrm{g})$ and dry weight (DW, g) of aerial parts and roots were measured. 


\subsection{Metabolites Determination}

\subsubsection{Extracts Preparation}

After air-dried roots, finely powdered aliquots $(0.2 \mathrm{~g})$ were soaked in ethanol $(95 \% \mathrm{v} / \mathrm{v}$, $20 \mathrm{~mL}$ ) and agitated at $25^{\circ} \mathrm{C}$ and $120 \mathrm{r} / \mathrm{min}$ for $72 \mathrm{~h}$. The homogenate was centrifuged (TGL$20 \mathrm{M}$, Changsha, China) at $4{ }^{\circ} \mathrm{C}$ and $5000 \mathrm{r} / \mathrm{min}$ for $10 \mathrm{~min}$. The extracts were increased to $25 \mathrm{~mL}$ with ethanol $(95 \% \mathrm{v} / \mathrm{v})$ for determination of ferulic acid, ligustilide, flavonoids and polysaccharides.

\subsubsection{Determination of Ferulic Acid and Ligustilide Contents}

Ferulic acid and ligustilide contents were determined according to the previous protocol [42]. Briefly, extracts $(10 \mu \mathrm{L})$ were determined at $323 \mathrm{~nm}$ using an HPLC Symmetry ${ }^{\circledR}$ $\mathrm{C}_{18}$ column $\left(250 \mathrm{~mm} \times 4.6 \mathrm{~mm}, 5 \mu \mathrm{m}\right.$; column temperature $30{ }^{\circ} \mathrm{C}$; Waters ACQUITY Arc, Milford, MA, USA). The solution of acetic acid (1.0\% v/v, A)-acetonitrile (B) was the mobile phase with gradient elution: $38-90 \% \mathrm{~B}$ (0-8 $\mathrm{min}), 90-38 \% \mathrm{~B}(8-12 \mathrm{~min})$ and $38 \% \mathrm{~B}(12-14 \mathrm{~min})$ at a flow rate of $1.0 \mathrm{~mL} / \mathrm{min}$. Ferulic acid and ligustilide contents were evaluated on peak area comparison with a reference standard. Representative HPLC chromatograms of standard reference and samples at 15 and $22{ }^{\circ} \mathrm{C}$ were shown in Figure S4.

\subsubsection{Determination of Flavonoids Content}

Flavonoids content was determined using the $\mathrm{NaNO}_{2}-\mathrm{AlCl}_{3}-\mathrm{NaOH}$ method $[43,44]$. Briefly, the extracts $(2.5 \mathrm{~mL})$ were added into ddH $\mathrm{H}_{2} \mathrm{O}(2 \mathrm{~mL})$ and $\mathrm{NaNO}_{2}(5 \% w / v, 0.3 \mathrm{~mL})$; after oscillation, and $\mathrm{AlCl}_{3}(10 \% w / v, 0.3 \mathrm{~mL})$ was added and reacted at $22{ }^{\circ} \mathrm{C}$ for $1 \mathrm{~min}$; then, $\mathrm{NaOH}(1.0 \mathrm{~mol} / \mathrm{L}, 2 \mathrm{~mL})$ was added to stop the reaction. An absorbance reader was taken at $510 \mathrm{~nm}$ using a spectrometer (V1800, Shanghai, China). Flavonoid content was expressed as milligram of catechin.

\subsubsection{Determination of Polysaccharides Content}

Polysaccharides content was determined using the sulfuric acid-phenol protocol method $[45,46]$. Briefly, the extracts $(150 \mu \mathrm{L})$ were added into a phenol reagent $(9 \% v / v$, $1 \mathrm{~mL})$; after oscillation, sulfuric acid $(3 \mathrm{~mL})$ was added and reacted at $22{ }^{\circ} \mathrm{C}$ for $30 \mathrm{~min}$. An absorbance reader was taken at $485 \mathrm{~nm}$ by using a spectrometer (V1800, Shanghai, China). Polysaccharides content was expressed as milligram of sucrose.

\subsubsection{Volatile Oils Determination}

The extract of volatile oils was conducted using a steam distillation method [47]. Briefly, air-dried roots powder $(5.0 \mathrm{~g})$ was soaked in $\mathrm{dH}_{2} \mathrm{O}(30 \mathrm{~mL})$ and extracted in a steam distillation apparatus for $8 \mathrm{~h}$; after $\mathrm{NaCl}(1.0 \mathrm{~g})$ added into the extracts and left standing for $10 \mathrm{~min}$, ethyl acetate $(30 \mathrm{~mL})$ was added; following exhaustive extraction $(\times 3)$, the upper portion was pooled, filtered and dried in vacuo at $35^{\circ} \mathrm{C}$ to evaporate ethyl acetate. The rate of volatile oils was expressed as extract volume $(\mathrm{mL})$ of roots weight $(\mathrm{g})$.

\subsection{Quantification of $m R N A$}

Total RNA was extracted from roots using a Plant RNA Kit (R6827, Omega Bio-Tek, Inc., Norcross, GA, USA). The quality of the total RNA was examined using $1.0 \%$ agarose gel electrophoresis. Based on RNA sequencing and analysis of bolting and flowering of A. sinensis in our previously published articles [48,49], 19 candidate genes involved in bioactive metabolite biosynthesis were dig out. Primer sequences for 19 candidate genes (Table 1) were designed using an NCBI Primer-BLAST tool. cDNA was synthesized using a FastKing RT kit (KR116, Tiangen, China), and qRT-PCR was performed by ABI QuantStudio 5 system (USA) with a SuperReal PreMix Plus (SYBR Green) (FP205, Tiangen, China). Actin was used as an internal reference. The relative expression level (REL) was evaluated based on a $2^{-\triangle \triangle \mathrm{Ct}}$ method [50]. 
Table 1. Primer sequences used in qRT-PCR analysis.

\begin{tabular}{|c|c|c|c|}
\hline Genes & Accession No. & Sequences $\left(5^{\prime}\right.$ to $\left.3^{\prime}\right)$ & Amplicon Size (bp) \\
\hline \multirow{2}{*}{$A C T$} & \multirow{2}{*}{ [26] } & Forward: TGGTATTGTGCTGGATTCTGGT & \multirow{2}{*}{109} \\
\hline & & Reverse: TGAGATCACCACCAGCAAGG & \\
\hline & & Ferulic acid Biosynthesis & \\
\hline \multirow{2}{*}{ PAL1 } & \multirow{2}{*}{ XM_017399483.1 } & Forward: GGACTTGACAGTAGGGCAG & \multirow{2}{*}{146} \\
\hline & & Reverse: CCCCGTAACTATCCGTTCCTT & \\
\hline \multirow{2}{*}{$4 C L L 4$} & \multirow{2}{*}{ XM_017376722.1 } & Forward: AAGCAGTGTTTCAGAGGCAG & \multirow{2}{*}{105} \\
\hline & & Reverse: GCTGAGCGCGGTATTGAGTT & \\
\hline \multirow{2}{*}{$4 C L L 5$} & \multirow{2}{*}{ XM_017388768.1 } & Forward: CGGGACGAGTAAAGGAGTGG & \multirow{2}{*}{171} \\
\hline & & Reverse: AGCGTTGCTACAAACCAAGC & \\
\hline \multirow{2}{*}{$4 C L L 7$} & \multirow{2}{*}{ KJ531407.1 } & Forward: TGCTCCGTTGGGTAGAGAGT & \multirow{2}{*}{164} \\
\hline & & Reverse: CTCCAGGCACAAGCATTCCT & \\
\hline \multirow{2}{*}{$4 C L L 9$} & \multirow{2}{*}{ XM_017397573.1 } & Forward: GGTGGGGAAGCTAACAGGTC & \multirow{2}{*}{183} \\
\hline & & Reverse: TCGCCAGTTCTTAACCAGCC & \\
\hline \multirow{2}{*}{ HCT } & \multirow{2}{*}{ XM_017397289.1 } & Forward: CCGGTGACATATCTGCGTGT & \multirow{2}{*}{171} \\
\hline & & Reverse: GCGGAATGGCAATGGAAAGG & \\
\hline \multirow{2}{*}{$\mathrm{C} 3 \mathrm{H}$} & \multirow{2}{*}{ [26] } & Forward: CAATCCAAGTTGACGACGAA & \multirow{2}{*}{119} \\
\hline & & Reverse: CGAAGGCGAAACATAGGC & \\
\hline \multirow{2}{*}{ ССОАMT } & AY6202451 & Forward: TCGGCTACGACAACACCCTA & 157 \\
\hline & AY $620 \angle 45.1$ & Reverse: TCGCCAACAGGAAGCATACA & $13 \%$ \\
\hline$C C P 1$ & YM 0171036171 & Forward: CCATTCATGGATGCGTTGGT & 125 \\
\hline CCKI & X11__01/40361/.1 & Reverse: CCACACGTCTCACATTGGCT & 135 \\
\hline COMT 1 & $\mathrm{XM} 0106730302$ & Forward: TGGCGGAAAGGTAGTCGTTG & 120 \\
\hline COMII & Alv1_0100/3030.2 & Reverse: TTCAGTCCTCTCACTTCCGC & 130 \\
\hline & & Flavonoid Biosynthesis & \\
\hline$C U C$ & KD7260141 & Forward: GCAAAGACGCTGCATCCAAA & 126 \\
\hline CHS & КР/26914.1 & Reverse: GGAGCTTGGTGAGCTGGTAG & 120 \\
\hline CHU & YM 0172651001 & Forward: GTGTTTCCCCAGCTGCAAAG & 100 \\
\hline$С \Pi 1$ & Alv1_01/3000109.1 & Reverse: TTCCGACTTCTGCTTTCCCA & 102 \\
\hline I'L & YM 017363271 & Forward: GGCCACCTTCACCTCATCAA & 172 \\
\hline $13 \mathrm{H}$ & XIN1_01/3632L/.1 & Reverse: GGGCGGTCAGCTAAAACAAC & $1 / 3$ \\
\hline$G T 6$ & YM 0172020001 & Forward: TTCGGTGCCCATCACAAGAA & 166 \\
\hline$G 10$ & AlV1_01/000000.1 & Reverse: AATCCTCCGACAGATGCGTG & 100 \\
\hline & & Volatile oils Biosynthesis & \\
\hline$D_{1}$ & גרת מחסח & Forward: CGCTAGTCTTTTGAGCGAAGC & 110 \\
\hline AINMII & B8KCD3.1 & Reverse: CATGGGCACCTCCTACATCC & 119 \\
\hline & (1) 1 & Forward: GATCAAGCCAGCAGTGATGC & 147 \\
\hline DEAI & 064908.1 & Reverse: ACTTCAACACGTGTAGGCCG & 147 \\
\hline & & Polysaccharide Biosynthesis & \\
\hline SHST 1 S & YM 0172627001 & Forward: ATGAAGTCCACACAGGAAGCC & 120 \\
\hline SUST & AIN_O1/003/U0.1 & Reverse: CGACGACAAGGTGATGAGTG & 124 \\
\hline Amu2 & VOP710 1 & Forward: TCTTCTGAGCCCTGGAGTGT & 117 \\
\hline Amyz & V00718.1 & Reverse: TCCAGGGAAGCCTCATGGAT & 117 \\
\hline$J U A Y$ & 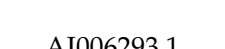 & Forward: GCACTCATCCTCCATTCAGAG & 167 \\
\hline WAXY & AJ000290.1 & Reverse: TCCGTTACTGATCCACCAGC & 167 \\
\hline
\end{tabular}




\subsection{Statistical Analysis}

All measurements were performed using three biological replicates. A $t$-test in SPSS 22.0 was performed for independent treatments with $p<0.05$ as the basis for statistical differences.

\section{Conclusions}

From the above observations, cooler temperatures significantly enhance biomass accumulation, ferulic acid and flavonoid biosynthesis in A. sinensis as well as their related genes expression while inhibiting polysaccharide accumulation. These findings will provide a strong foundation for regulating plant growth and bioactive metabolites production of $A$. sinensis. The roles of sunshade and rainfall in the geo-authentic formation will be conducted in the upcoming studies.

Supplementary Materials: The following supporting information can be downloaded online. Figure supplemental legends: Figure S1: Seedlings of A. sinensis (cultivar Mingui 1) with root-tip diameter 0.4-0.5 cm; Figure S2: Plantlets contained two leaves after 15 days; Figure S3: Plants treated at 15 and $22^{\circ} \mathrm{C}$ after 30 days; Figure S4: Representative HPLC chromatograms of standard and samples at $15^{\circ} \mathrm{C}$ and $22^{\circ} \mathrm{C}$. A and B represent ferulic acid and ligustilide.

Author Contributions: Data curation, methodology, investigation and writing-original draft preparation, H.D.; data curation and formal analysis, M.L. (Meiling Li); resources, L.J.; supervision and project administration, X.X.; conceptualization and writing_-review and editing, M.L. (Mengfei Li); conceptualization and writing - review and editing, J.W. All authors have read and agreed to the published version of the manuscript.

Funding: This research was financially supported by funds from the National Natural Science Foundation of China (32160083); China Agriculture Research System of MOF and MARA (CARS-21); State Key Laboratory of Aridland Crop Science Gansu Agricultural University (GSCS-2021-Z03); Key talent projects of Gansu Province, China (2020RCXM103); and Assurance Project of Ecological Planting and Quality of Daodi Herbs (202103003).

Institutional Review Board Statement: Not applicable.

Conflicts of Interest: The authors declare that there are no conflicting interest.

Sample Availability: Samples of Angelica sinensis seeds and seedlings are available from authors.

\section{References}

1. Upton, R. American Herbal Pharmacopoeia and Therapeutic Compendium: Dang Gui Root-Angelica Sinensis (Oliv.); American Herbal Pharmacopoeia and Therapeutic Compendium: Scotts Valley, CA, USA, 2003; pp. 1-41.

2. Zhang, H.Y.; Bi, W.G.; Yu, Y.; Liao, W.B. Angelica sinensis (Oliv.) Diels in China: Distribution, cultivation, utilization and variation. Genet. Resour. Crop Evol. 2012, 59, 607-613. [CrossRef]

3. Chinese Pharmacopoeia Commission. Pharmacopoeia of the People's Republic of China (2015 Version) Volume I; Chinese Medical Science Press: Beijing, China, 2020; p. 139.

4. Wei, W.L.; Zeng, R.; Gu, C.M.; Qu, Y.; Huang, L.F. Angelica sinensis in China-A review of botanical profile, ethnopharmacology, phytochemistry and chemical analysis. J. Ethnopharmacol. 2016, 190, 116-141. [CrossRef]

5. Hook, I.L.I. Danggui to Angelica sinensis root: Are potential benefits to European women lost in translation? A review. J. Ethnopharmacol. 2014, 152, 1-13. [CrossRef]

6. Xu, X.Q.; Zhang, X.B.; Chen, J.; Zhao, W.L.; Jin, L. Study on ecological suitability of Angelica sinensis in Gansu Province. Chin. Tradit. Herb. Drugs 2020, 51, 3304-3307.

7. Liang, F.; Li, J.; Zhang, W.; Zhang, R.X. Causes for change in producing areas of geo-authentic herbs. China J. Chin. Mat. Med. 2013, 38, 1649-1651.

8. Huang, L.Q.; Jin, L. Suitable Technology for Production and Processing of Angelica sinensis; China Pharmaceutical Science and Technology Press: Beijing, China, 2018; pp. 1-14.

9. Xu, X.Q.; Zhu, T.T.; Shi, T.T.; Chen, J.; Jin, L. Quality suitability regionalization analysis of Angelica sinensis in Gansu, China. PLoS ONE 2020, 15, 0243750. [CrossRef] [PubMed]

10. Fan, Q.; Zhang, Y.Y.; Chen, H.P.; Lin, X.Y.; Xia, P.F.; Sun, Y.J; Zhao, L.; Luo, J.; Yang, F.X.; Li, S.H. Influence of ecological factors on the quality of Angelica sinensis based on OPLS model. Chin. Tradit. Pat. Med. 2021, 43, 1226-1230. 
11. Jin, L.; Jin, Y.; Wang, H.Z.; Zhang, X.F.; Zhang, P.S.; Li, Y.D. Effects of altitude on the yield and content of ferulic acid in Angelica sinensis. J. Tradit. Chin. Vet. Med. 2014, 3, 47-49.

12. Li, M.S.; Hao, Y.R.; Zhang, Z.G. Influence of the high altitude on the yield of Angelica sinensis and principal components of essential oils. Acta Bot. Boreali-Occidentalia Sin. 1985, 5, 155-160.

13. Li, J.; Gao, S.F.; Li, Y.D.; Jin, L.; Wang, H.Z. Response study of ferulic and ligustilide in the root of Angelica sinensis on altitude. J. Gansu Coll. TCM 2014, 31, 23-26.

14. Li, M.F.; Liu, X.Z.; Wei, J.H.; Zhang, Z.; Chen, S.J.; Liu, Z.H.; Xing, H. Selection of high altitude planting area of Angelica sinensis based on biomass, bioactive compounds accumulation and antioxidant capacity. Chin. Tradit. Herb. Drugs 2020, 51, 474-481.

15. Li, M.F.; Kang, T.L.; Jin, L.; Wei, J.H. Research progress on bolting and flowering of Angelica sinensis and regulation pathways. Chin. Tradit. Herb. Drugs 2020, 51, 5894-5899.

16. Ma, Y.; Jin, L.; Wang, Z.H.; Cui, Z.J.; Zhang, Y.L.; Li, Y.D. Comparative study of cultivated radix Angelica sinensis polysaccharide content from different altitude in Min county of Gansu province. J. Tradit. Chin. Vet. Med. 2013, 2, 7-9.

17. Wang, H.Z.; Jin, L.; Zhang, E.H. Effect of altitude on the photosynthate accumulation and distribution pattern of Angelica sinensis. J. Chin. Med. Mater. 2012, 35, 1191-1194.

18. Wang, H.Z.; Jin, L.; Zhang, E.H. Effect of altitude on ferulic acid in Angelica sinensis and analysis in key factors. Chin. Tradit. Herb. Drugs 2013, 44, 219-223.

19. Lin, H.M.; Wu, Y.A.; Cao, Z.F.; Lv, S.L.; Mao, X.J. Influence of sun shade cultivation on premature bolting in Angelica sinensis and growth environment factors. Chin. J. Exp. Tradit. Med. Form. 2010, 16, 79-83.

20. Xiang, H.; Li, Y.; Jin, Y. Effects of light intensity on yield and ferulic acid content in Angelica sinensis. J. Tradit. Chin. Vet. Med. 2015, $2,53-54$.

21. Wang, Z.H.; Wang, Y.Q.; Fan, Q.; Yang, X.; Luo, J.; Li, S.N.; Jia, M.T. Effects of UV-B radiation on the content of phthalides in Angelica sinensis. J. Gansu Coll. TCM 2019, 36, 31-34.

22. Liu, B.; Rao, B.Y.; Qian, C.; Wu, Z.J. Effect on different irrigation treatments on growth, yield and quality of Angelica sinensis. Mod. Agric. Sci. Tech. 2013, 2, 77-82.

23. Bohnert, H.J.; Nguyen, H.; Lewis, N.G. Bioengineering and Molecular Biology of Plant. Pathways; Science Press: Beijing, China, 2008; pp. 385-401.

24. Liu, J.; Li, W.J.; Wang, C.M.; Xie, H.M. Biosynthesis and regulation of ferulic acid in Angelica sinensis. Chin. Tradit. Herb. Drugs 2008, 39, 1909-1912.

25. Turi, C.E.; Murch, S.J. Targeted and untargeted phytochemistry of Ligusticum canbyi: Indoleamines, phthalides, antioxidant potential, and use of metabolomics as a hypothesis-generating technique for compound discovery. Planta Med. 2013, 79, 1370-1379. [CrossRef] [PubMed]

26. Xu, R.; Xu, J.; Li, Y.C.; Dai, Y.T.; Zhang, S.P.; Wang, G.; Liu, Z.G.; Dong, L.L.; Chen, S.L. Integrated chemical and transcriptomic analyses unveils synthetic characteristics of different medicinal root parts of Angelica sinensis. Chin. Herb. Med. 2019, 12, 19-28. [CrossRef]

27. Liang, F.; Li, J.; Zhang, W.; Zhang, R.X. Brief introduction of geo-authentic herbs. China J. Chin. Mat. Med. 2013, 38, 1455-1457.

28. Yang, D.L.; Sun, P.; Li, M.F. Chilling temperature stimulates growth, gene over-expression and podophyllotoxin biosynthesis in Podophyllum hexandrum Royle. Plant Physiol. Biol. 2016, 107, 197-203. [CrossRef]

29. Yu, K.W.; Murthy, H.N.; Hahn, E.J.; Paek, K.Y. Ginsenoside production by hairy root cultures of Panax ginseng: Influence of temperature and light quality. Biol. Eng. J. 2005, 23, 53-56. [CrossRef]

30. Su, H.Y.; Li, J.; Chen, S.J.; Sun, P.; Xing, H.; Yang, D.L.; Zhang, X.N.; Li, M.F.; Wei, J.H. Physiological and transcriptomic analysis provide insight into low temperature enhancing hypericin biosynthesis in Hypericum perforatum. Molecules 2021, $26,2294$. [CrossRef]

31. Ramakrishna, A.; Ravishankar, G.A. Influence of abiotic stress signals on secondary metabolites in plants. Plant Signal. Behav. 2011, 6, 1720-1731.

32. Dixon, R.A.; Paiva, N.L. Stress-induced phenylpropanoid metabolism. Plant Cell 1995, 7, 1085-1097. [CrossRef]

33. Kienow, L.; Schneider, K.; Bartsch, M.; Stuible, H.P.; Weng, H.; Miersch, O.; Wasternack, C.; Kombrink, E. Jasmonates meet fatty acids: Functional analysis of a new acyl-coenzyme A synthetase family from Arabidopsis thaliana. J. Exp. Bot. 2008, 59, 403-419. [CrossRef] [PubMed]

34. Liu, T.; Yao, R.; Zhao, Y.; Xu, S.; Huang, C.; Luo, J.; Kong, L. Cloning, functional characterization and site-directed mutagenesis of 4-coumarate: Coenzyme a ligase (4CL) involved in coumarin biosynthesis in Peucedanum praeruptorum Dunn. Front. Plant Sci. 2017, 8, 4. [CrossRef]

35. Griesser, M.; Vitzthum, F.; Fink, B.; Bellido, M.L.; Raasch, C.; Munoz-Blanco, J.; Schwab, W. Multi-substrate flavonol Oglucosyltransferases from strawberry (Fragaria $\times$ ananassa) achene and receptacle. J. Exp. Bot. 2008, 59, 2611-2625. [CrossRef]

36. Liu, C.J.; Huhman, D.; Sumner, L.W.; Dixon, R.A. Regiospecific hydroxylation of isoflavones by cytochrome p450 $81 \mathrm{E}$ enzymes from Medicago truncatula. Plant J. 2003, 36, 471-484. [CrossRef]

37. Koeduka, T.; Baiga, T.J.; Noel, J.P.; Pichersky, E. Biosynthesis of t-anethole in anise: Characterization of $t$-anol/isoeugenol synthase and an O-methyltransferase specific for a C7-C8 propenyl side chain. Plant Physiol. 2009, 149, 384-394. [CrossRef] [PubMed]

38. Dudareva, N.; D’Auria, J.C.; Nam, K.H.; Raguso, R.A.; Pichersky, E. Acetyl-CoA: Benzylalcohol acetyltransferase-An enzyme involved in floral scent production in Clarkia breweri. Plant J. 1998, 14, 297-304. [CrossRef] 
39. Miron, D.; Schaffer, A.A. Sucrose phosphate synthase, sucrose synthase, and invertase activities in developing fruit of Lycopersicon esculentum Mill. and the sucrose accumulating Lycopersicon hirsutum Humb. and Bonpl. Plant Physiol. 1991, 95, 623-627. [CrossRef] [PubMed]

40. Visser, R.G.; Stolte, A.; Jacobsen, E. Expression of a chimaeric granule-bound starch synthase-GUS gene in transgenic potato plants. Plant Mol. Biol. 1991, 17, 691-699. [CrossRef] [PubMed]

41. Date, K.; Satoh, A.; Iida, K.; Ogawa, H. Pancreatic $\alpha$-Amylase controls glucose assimilation by duodenal retrieval through N-Glycan-specific binding, endocytosis, and degradation. J. Biol. Chem. 2015, 290, 17439-17450. [CrossRef]

42. Deng, X.Q.; Guan, X.J.; Huang, N.N.; Li, J. Simultaneous determination of eight constituents in Angelica sinensis by HPLC. Chin. Tradit. Pat. Med. 2020, 42, 2075-2079.

43. Lay, M.M.; Karsani, S.A.; Mohajer, S.; Abd Malek, S.N. Phytochemical constituents, nutritional values, phenolics, flavonols, flavonoids, antioxidant and cytotoxicity studies on Phaleria macrocarpa (Scheff.) Boerl fruits. BMC Complement. Altern. Med. 2014, 14, 152. [CrossRef]

44. Lv, M.; Su, H.Y.; Li, M.L.; Yang, D.L.; Yao, R.Y.; Li, M.F.; Wei, J.H. Effect of UV-B radiation on growth, flavonoid and podophyllotoxin accumulation, and related gene expression in Sinopodophyllum hexandrum. Plant Biol. 2021, 23, 202-209. [CrossRef]

45. Dubois, M.; Gilles, K.A.; Hamilton, J.K.; Rebers, P.A.; Smith, F. Colorimetric method for determination of sugars and related substances. Anal. Chem. 1956, 28, 350-356. [CrossRef]

46. Cao, X.L.; Li, M.L.; Li, J.; Song, Y.X.; Zhang, X.N.; Yang, D.L.; Li, M.F.; Wei, J.H. Co-expression of hydrolase genes improves seed germination of Sinopodophyllum hexandrum. Ind. Crops Prod. 2021, 164, 113414. [CrossRef]

47. Zheng, W.R.; Tao, Y.H.; Shi, J.; Shao, J.; Xiao, W. Optimize the technique of extracting volatile oil from Angelica sinensis by steam distillation. Mod. Chin. Med. 2013, 15, 879-882.

48. Li, J.; Li, M.L.; Zhu, T.T.; Zhang, X.N.; Li, M.F.; Wei, J.H. Integrated transcriptomics and metabolites at different growth stages reveals the regulation mechanism of bolting and flowering of Angelica sinensis. Plant Biol. 2021, 23, 574-582. [CrossRef]

49. Li, M.F.; Li, J.; Wei, J.H.; Paré, P.W. Transcriptional controls for early bolting and flowering in Angelica sinensis. Plants 2021, 10, 1931. [CrossRef]

50. Willems, E.; Leyns, L.; Vandesompele, J. Standardization of real-time PCR gene expression data from independent biological replicates. Anal. Biol. 2008, 379, 127-129. [CrossRef] [PubMed] 